\title{
Meta-Analysis of the Effects of Triazole-Based Fungicides on Wheat Yield and Test Weight as Influenced by Fusarium Head Blight Intensity
}

\author{
P. A. Paul, M. P. McMullen, D. E. Hershman, and L. V. Madden
}

First and fourth authors: Department of Plant Pathology, The Ohio State University, Ohio Agricultural Research and Development Center, Wooster 44691; second author: Department of Plant Pathology, North Dakota State University, Fargo 58108; and third author: Department of Plant Pathology, University of Kentucky, Princeton 42445.

Accepted for publication 2 October 2009.

\begin{abstract}
Paul, P. A., McMullen, M. P., Hershman, D. E., and Madden, L. V. 2010. Meta-analysis of the effects of triazole-based fungicides on wheat yield and test weight as influenced by Fusarium head blight intensity. Phytopathology 100:160-171.

Multivariate random-effects meta-analyses were conducted on 12 years of data from 14 U.S. states to determine the mean yield and test-weight responses of wheat to treatment with propiconazole, prothioconazole, tebuconazole, metconazole, and prothioconazole+tebuconazole. All fungicides led to a significant increase in mean yield and test weight relative to the check ( $\bar{D} ; P<0.001)$. Metconazole resulted in the highest overall yield increase, with a $\bar{D}$ of $450 \mathrm{~kg} / \mathrm{ha}$, followed by prothioconazole+tebuconazole $(444.5 \mathrm{~kg} / \mathrm{ha})$, prothioconazole $(419.1 \mathrm{~kg} / \mathrm{ha})$, tebuconazole $(272.6 \mathrm{~kg} / \mathrm{ha})$, and propiconazole $(199.6 \mathrm{~kg} / \mathrm{ha})$. Metconazole, prothioconazole+tebuconazole, and prothioconazole also resulted in

significantly affected the yield response to treatment; depending on the fungicide, $\bar{D}$ was 110.0 to $163.7 \mathrm{~kg} / \mathrm{ha}$ higher in spring than in soft-red winter wheat. Fusarium head blight (FHB) disease index (field or plotlevel severity) in the untreated check plots, a measure of the risk of disease development in a study, had a significant effect on the yield response to treatment, in that $\bar{D}$ increased with increasing FHB index. The probability was estimated that fungicide treatment in a randomly selected study will result in a positive yield increase $\left(p_{+}\right)$and increases of at least 250 and $500 \mathrm{~kg} / \mathrm{ha}\left(p_{250}\right.$ and $p_{500}$, respectively). For the three most effective fungicide treatments (metconazole, prothioconazole+tebuconazole, and prothioconazole) at the higher selected FHB index, $p_{+}$was very large (e.g., $\geq 0.99$ for both wheat types) but $p_{500}$ was considerably lower (e.g., 0.78 to 0.92 for spring and 0.54 to 0.68 for soft-red winter wheat); at the lower FHB index, $p_{500}$ for the same three fungicides was 0.34 to 0.36 for spring and only 0.09 to 0.23 for soft-red winter wheat.
\end{abstract} the highest increases in test weight, with $\bar{D}$ values of 17.4 to $19.4 \mathrm{~kg} / \mathrm{m}^{3}$, respectively. On a relative scale, the best three fungicides resulted in an overall 13.8 to $15.0 \%$ increase in yield but only a 2.5 to $2.8 \%$ increase in test weight. Except for prothioconazole+tebuconazole, wheat type
Additional keywords: baseline risk, Fusarium graminearum, Gibberella zeae, risk analysis, wheat scab.

Depending on the wheat class and active ingredient, mean percent disease and toxin reduction relative to the untreated check was 38 to $58 \%$ for FHB index and 38 to $52 \%$ for DON. In some years, this level of control is sufficient to minimize yield and quality losses and offset the cost of fungicide application. However, in years when conditions are highly favorable for infection (high inoculum density and wet, humid weather during anthesis), yield and quality losses may still be high in fields treated with the best of the currently available fungicides.

Uncertainties as to the economic benefit of applying a fungicide have influenced fungicide-use decisions and have contributed to fungicides not being used routinely to manage FHB and DON in most wheat-producing regions of the United States. The economic benefit of fungicide application varies and depends on several factors. These include the baseline levels of disease and DON, fungicide efficacy in terms of disease and DON reduction, the yield and quality benefits of the application, discount schedules at local elevators, grain prices, and the cost of fungicide and application. Considerable effort and resources have gone into evaluating the effects of fungicides on FHB and DON. As a result, quantitative estimates of the overall efficacy of the best active ingredients based on percent FHB and DON reduction are available $(32,33)$. Although grain yield and test-weight data are usually collected in fungicide trials, less is known about the overall effects of fungicides on these responses and whether fungicides with similar efficacy for disease or DON reduction differ in their effects on yield and test weight. Also, the development of foliar

doi:10.1094/PHYTO-100-2-0160

(C) 2010 The American Phytopathological Society 
and other head diseases in trials often makes it difficult to assess the yield and quality impact specifically associated with FHB and DON.

Quantitative estimates of the yield and quality responses to fungicide treatments are critical for evaluating the economic benefit of chemical and integrated FHB-DON management strategies and, along with fungicide costs, are important for helping producers choose among products. We report herein the results of a formal quantitative synthesis, through a multivariate meta-analysis $(1,2,33,39,44)$, of data from 12 years of FHB-DON UFTs. The objectives were to (i) evaluate the overall mean yield and testweight responses of wheat to triazole-based fungicides applied for FHB and DON management and (ii) determine whether the responses were influenced by wheat type and background disease levels.

\section{MATERIALS AND METHODS}

Database for meta-analysis. The data used in this investigation were collected from UFTs of the U.S. Wheat and Barley Scab Initiative (USWBSI) and similar studies conducted between 1995 and 2007. A detailed description of the UFTs for the years up to 2005 has been previously published $(32,33)$. Since the writing of the previous meta-analysis papers, results from two more years have become available. In brief, UFTs were conducted in fields across the U.S. soft winter-wheat-producing region (MidAtlantic, southern, and Midwestern regions not including Iowa, Minnesota, and the Dakotas) and spring-wheat-producing region and consisted of a series of coordinated experiments conducted according to a standard protocol, using a susceptible or moderately susceptible cultivar and agronomic practices appropriate for each location. Plots were either planted into corn or wheat residue or artificially infested with $F$. graminearum-infested kernels and mist irrigated as a means of enhancing inoculum production, infection, and disease development. FHB index (mean percentage of diseased spikelets per spike) was assessed at Feeke's plant growth stage (GS) 11.2 (soft dough) (17) on 20 to 50 spikes per plot. Plots were harvested using a research plot combine and average yield and test weight was determined for each treatment.

The specific fungicide active ingredient, application timing, and rate of active ingredient per unit area varied from year to year and among studies; however, in any given year, a core set of treatments was applied in all studies and an untreated check was used as the control. A fixed set of criteria was used to select studies for inclusion in the analysis and to determine which treatments to consider. To be selected, a study had to have at least one triazole-based fungicide with one or more of the active ingredients tebuconazole, propiconazole, prothioconazole, and metconazole; along with some measure of yield (volume or weight per unit area) for the untreated check and at least one of the fungicide treatments. A large subset of the studies with yield data also had test weight and FHB index data. From 1995 to 2004, $\approx 54 \%$ of the studies recorded yield data; from 2005 through 2007, 100\% of the studies recorded yield. From the selected group of studies, only treatments that consisted of a single ground application at anthesis (Feekes' GS 10.5.1) were considered. For those active ingredients applied at multiple rates as separate treatments in the same study, only the most effective rate, based on mean disease index, was considered for analysis. All rates were within the range of currently recommended rates for each active ingredient.

Collectively, there were six treatments in the final group of studies analyzed, five fungicide treatments plus the untreated check. Tebuconazole was tested as Folicur 3.6 F (Bayer Cropscience, Research Triangle Park, NC), propiconazole was tested as Tilt 3.6 EC (Syngenta Crop Protection Inc., Greensboro, NC), metconazole was tested under the trade name Caramba 90 SL (BASF Corporation Agricultural Products, Research Triangle Park, NC) or as an experimental product (BAS555 or V-10116), prothioconazole was tested either as Proline 480 SC (Bayer Cropscience) or as an experimental product (AMS21619 or JAU6476), and a combination product of tebuconazole+prothioconazole was tested either as a premix under the trade name Prosaro 421 SC (Bayer Cropscience) or as a tank mix of Folicur $3.6 \mathrm{~F}$ and Proline $480 \mathrm{SC}$ or Folicur $3.6 \mathrm{~F}$ and one of the experimental prothioconazoles. After the selection, the number of treatments in any individual study ranged from two to six. Tebuconazole and prothioconazole were the most- and least-frequently occurring treatments, respectively. For every treatment, there were more studies from soft-red winter-wheat regions than from spring-wheat regions. Tebuconazole was tested in 136 (78 winter and 58 spring) studies for its effect on yield and 120 (63 winter and 57 spring) studies for its effect on test weight, propiconazole in 57 (30 winter and 27 spring) studies for yield and 52 (26 from each wheat class) studies for test weight, prothioconazole in 56 (37 winter and 19 spring) studies for yield and 47 (29 winter and 18 spring) studies for test weight, tebuconazole+prothioconazole in 87 (50 winter and 37 spring) studies for yield and 78 (42 winter and 36 spring) studies for test weight, and metconazole in 86 (46 winter and 40 spring) studies for yield and 83 (43 winter and 40 spring) studies for test weight.

Quantitative synthesis of fungicide effects on grain yield and test weight. Mean grain yield and test weight data from fungicide-treated and untreated check plots were used to generate (estimated) effect sizes (18) for evaluating the effect of fungicides on yield and test weight. Using the untreated check as the reference, we computed unstandardized mean difference (18) as the effect size for this analysis. For a single study, if $\bar{X}_{\text {Check }}$ is the mean of yield or test weight for the untreated check, and $\bar{X}_{\text {Treated }}$ is the mean of yield or test weight for a treatment (where "Treated" corresponds to either tebuconazole [TEBU], propiconazole [PROP], prothioconazole [PROT], tebuconazole+ prothioconazole [TEBU+PROT], or metconazole [METC]), then the (estimated) effect size $(D)$ is defined simply as $D=\bar{X}_{\text {Treated }}-\bar{X}_{\text {Check }}$.

Because there were multiple treatments and, consequently, a separate $D$ value for each treatment in each study, with all the $D$ values being correlated within studies, we opted to use a multivariate meta-analytic approach $(1,2,39,44)$ in this investigation instead of the more commonly utilized univariate approach (8, $16,18,34)$. For reasons discussed elsewhere $(2,24,40)$, the multivariate approach is considered more efficient and more appropriate statistically than the univariate approach for analyzing a data set with several effect sizes of interest. The multivariate approach is especially beneficial in obtaining precise and accurate mean effect-size estimates when all treatments are not found in all studies $(20,40,45)$, which is the situation with our investigation.

A vector of responses consisting of treatment means for yield and test weight was used for each study. For a single study, the response vector is given by

$$
\mathbf{Y}=\left(\begin{array}{l}
\bar{X}_{\text {TEBU }} \\
\bar{X}_{\text {PROP }} \\
\bar{X}_{\text {PROT }} \\
\bar{X}_{\text {TEBU }+ \text { PROT }} \\
\bar{X}_{\text {METC }} \\
\bar{X}_{\text {Check }}
\end{array}\right)
$$

The mean for treatment $j$ ( $j=$ TEBU, PROP, PROT, TEBU+PROT, METC, and Check) is specified by $Y_{j}$. The variance of the mean for an individual study, known as the within-study or sampling variance, is given by $s_{j}^{2}=V / n$, where $n$ is number of replicates (usually $n=4$ ), and $V$ is the residual variance or mean square error from the primary analysis of yield or test weight in a study. 
With $K$ studies in the meta-analysis, one can define the response for the $i$ th study $(i=1, \ldots, K)$ and the $j$ th treatment as $Y_{i j}=\bar{X}_{i j}$, and the vector of responses for the $i$ th study as $\mathbf{Y}_{i}$. The within-study (sampling) variance for the $i$ th study and the $j$ th treatment is given by $s_{i j}^{2}$, and the within-study variance-covariance matrix is given as $\mathbf{S}_{i}$ (which is different for each study). The diagonal elements of $\mathbf{S}_{i}$ are $s_{i j}^{2}$, and the off-diagonal elements are 0 . The mean (expected value) of the response vector $\mathbf{Y}_{i}$ over the $K$ studies is represented by parameter vector $\boldsymbol{\mu}$. The elements of $\boldsymbol{\mu}$ are the individual mean or expected values for the different treatments across the $K$ studies:

$$
\boldsymbol{\mu}=\left(\begin{array}{l}
\mu_{T E B U} \\
\mu_{P R O P} \\
\mu_{P R O T} \\
\mu_{T E B U+P R O T} \\
\mu_{M E T C} \\
\mu_{\text {Check }}
\end{array}\right)
$$

The estimates of the elements of $\boldsymbol{\mu}$ are the estimated means of the $Y$ values across all the studies (i.e., $\hat{\mu}_{j}=\bar{Y}_{j}$ ).

In the meta-analysis, we assumed that $\mathbf{Y}_{i}$ has a multivariate normal distribution with mean vector $\boldsymbol{\mu}$ and variance-covariance matrix $\Sigma+\mathbf{S}_{i}$, where $\Sigma$ is a six-by-six between-study variancecovariance matrix. The model can be written as

$$
\mathbf{Y}_{i} \sim N\left(\boldsymbol{\mu}, \Sigma+\mathbf{S}_{i}\right)
$$

where $N(\bullet)$ indicates a multivariate normal distribution. We used an unstructured matrix for $\Sigma$, in the sense that there were no constraints placed on the variances for each treatment and covariances for pairs of treatments. Equation 1 was fitted to the data from the total of 136 studies with the MIXED procedure of SAS (19), as described by van Houwelingen et al. (44) and Paul et al. (33), using maximum likelihood. With maximum-likelihood parameter estimation, results from all treatments of all studies were utilized, even though all treatments do not occur in every study $(1,40)$. The within-study variances (the elements of $\mathbf{S}_{i}$ ) were incorporated into the model fitting procedure by weighting each observation by the inverse of the within-study variance $\left(s_{i j}^{2}\right)$. The mean effect size of interest (across all studies), $\bar{D}$, was the difference between pairs of elements of $\boldsymbol{\mu}$. For instance, $\bar{D}$ for prothioconazole was estimated as $\bar{D}_{P R O T}=\hat{\mu}_{P R O T}-\hat{\mu}_{\text {Check }}=\bar{Y}_{P R O T}-\bar{Y}_{\text {check }}$. Both contrast and lsmeans statements in MIXED were utilized to obtain the contrast estimates for all the treatments relative to the check ( $\bar{D}$ values), as well as the associated standard errors and $95 \%$ confidence intervals. The standard errors were based on the within- and between-subject variances and between-subject covariances (45). A standard normal test statistic $(Z)(9,18,32,33)$ was used to determine whether the mean differences $(\bar{D})$ were significantly different from zero for each of the treatments, for both yield and test weight. Note that, in terms of notation in the body of the text, $D$ (without an overstrike "bar") is used for the effect size within a study (with subscripts, as needed, to designate the relevant fungicide treatment, response variable, or other conditions), and $\bar{D}$ is used for the mean or estimated expected effect size across all studies (with subscripts used, again, as needed for clarity).

A fixed-effects meta-analysis model was also fitted to the data to determine whether there was significant between-study variability. This model is the same as equation 1 , but with 0 for the elements of the matrix $\Sigma$. A likelihood-ratio test was performed (based on the difference in the log-likehoods between the two models) (19) to determine whether there were significant (nonzero) random effects of study on the response vectors. To determine the extent and impact of the among-study variability on the mean effect sizes and their confidence intervals, the $R^{2}$ statistic (this is not the standard coefficient of determination) of Higgins et al. (13) was calculated.

Influence of wheat type and FHB index on the effect sizes. The multivariate meta-analysis model was expanded to determine whether the magnitude of the effect sizes (e.g., $\bar{D}_{P R O T}$ ) changed with wheat type and the magnitude of FHB index in the untreated check. Studies were classified as spring and winter wheat studies based on the wheat type used. Wheat type was then used as a categorical moderator variable in the analysis. In particular, we define $T_{i}$ as the wheat type for study $i$, with $T_{i}=1$ if spring and $T_{i}=0$ if winter. In contrast, FHB index in the untreated check for the $i$ th study $\left(B_{i}\right)$ was used as a continuous moderator variable. $B_{i}$ can be considered a baseline risk variable (1), an indication of overall favorability of conditions in the study for development of wheat scab epidemics.

A multivariate meta-analysis model was refitted to the data utilizing the moderator variables. Both moderator variables were considered fixed effects in the analysis. The effect of the moderator variable for the $i$ th study on the response vector is given by the vector $\delta_{i}$, with six rows (for the six treatments, including the check). The model in equation 1 can be rewritten as

$$
\mathbf{Y}_{i} \sim N\left(\boldsymbol{\mu}+\boldsymbol{\delta}_{i}, \Sigma+\mathbf{S}_{i}\right)
$$

where all other terms are as defined previously. With the moderator variables in the model, the magnitude of the expected means for yield or test weight for each treatment depended on the moderator variables in the particular study $\left(\boldsymbol{\mu}+\boldsymbol{\delta}_{i}\right)$. Elements of vector $\delta_{i}$ (i.e., $\boldsymbol{\delta}_{i j}$, with, as before, $j=$ TEBU, PROP, PROT, TEBU+PROT, METC, and Check) depended on the specific levels of the moderator variables (e.g., spring versus winter wheat) for the $i$ th study. For instance, for treatment $j$ of study $i$, the effect can be written as

$$
\delta_{i j}=\tau_{j} T_{i}+\mathrm{l}_{j} B_{i}
$$

where $\tau_{j}$ is the effect of wheat type on expected yield (or test weight), and $\imath_{j}$ is the effect of FHB index in the check (the baseline risk). Because $\tau$ and $\mathrm{l}$ can vary with treatment (as specified by the $j$ subscript), the difference between two treatment means (the effect size of interest) can also depend on the specific wheat type or level of FHB index in the check (depending on the estimates of $\tau_{j}$ and $\boldsymbol{r}_{j}$ ). Note that the model in equations 2 and 3 for effects of baseline disease index on yield is different from models for yield in a field or plot as a function of disease intensity in the same plot (21). The baseline disease index is, by definition, the same for all treatments within a study, because it is used to represent study-level conditions that may be influencing the effect sizes.

Separate analysis was performed for yield and test weight. For each response, the analysis was first conducted with wheat type as the moderator variable and then repeated with both wheat type and mean FHB index in the check as moderator variables. Equation 2 was fitted to the data with maximum likelihood using the MIXED procedure of SAS, with the same (within-study) weights as above used in fitting the models. Contrast and estimate statements in MIXED were used to estimate the mean effect sizes (i.e., mean difference for each treatment relative to the check; $\bar{D}$ ) for each wheat class and for selected values of FHB index (e.g., 5 and $30 \%)$; standard errors and confidence intervals were likewise calculated for these mean effect sizes. As an example contrast, the estimated mean effect size for prothioconazole with spring wheat when FHB index is $30 \%$ is given by

$$
\bar{D}_{P R O T, S, 30}=\left(\hat{\mu}_{\text {PROT }}+1 \hat{\tau}_{\text {PROT }}+30 \hat{\imath}_{\text {PROT }}\right)-\left(\hat{\mu}_{\text {Check }}+1 \hat{\tau}_{\text {Check }}+30 \hat{\imath}_{\text {Check }}\right)
$$


To determine whether wheat type and mean FHB index in the control had a significant effect on mean differences (the effect sizes), $\chi^{2}$ tests were used. These tests were performed using additional contrast statements in the MIXED procedure.

Using the estimated mean effect size for yield $(\bar{D})$, we estimated the probability that the increase in yield from applying a fungicide in a new randomly selected study $\left(D_{\text {new }}\right)$ - done in the same manner as the studies considered in this analysiswill be $>0$ (i.e., $\left.p_{+}=\operatorname{Prob}\left[D_{\text {new }}>0\right]\right),>250 \mathrm{~kg} / \mathrm{ha}\left(p_{250}=\right.$ $\left.\operatorname{Prob}\left[D_{\text {new }}>250\right]\right)$, and $>500 \mathrm{~kg} / \mathrm{ha}\left(p_{500}=\operatorname{Prob}\left[D_{\text {new }}>500\right]\right)$. These cut-off constants correspond to 0 and $\approx 4$ and 8 bushels/acre of harvested grain yield. The calculations, which require the estimate of the among-study variance for the effect size, were done using the methods described on page 1,003 of Paul et al. (33). These estimates were determined for each fungicide treatment.

Percent change in yield and test weights relative to the check. Sometimes, disease and toxin responses to fungicide treatment are given as percent changes relative to a reference value (such as the response for the nonsprayed control). This is especially valuable when the variation (across studies) is large, which occurs for FHB index and DON as responses. For instance, the coefficient of variation (CV) of FHB index in the controls across all studies was $106 \%$ and the CV of DON was $126 \%$. In contrast, the $\mathrm{CV}$ for yield in the checks was $37 \%$ and, for test weight, $10 \%$ (L. V. Madden, unpublished data). Because of the relatively low variation in yield (and test weight), and because economic income for a crop is based on actual yield (in volume or weight) per unit area as well as test weight, we based our primary analysis on differences as effect sizes.

However, in order to more directly compare the treatment effects on yield (or test weight) with the previously reported effects on index or DON (33), we repeated some analyses to obtain the percent increase in yield (or test weight) for a given treatment relative to the yield (or test weight) for the control. The steps in the meta-analysis were identical to those described above, except that the $Y_{i j}$ response was the $\log$ of mean yield (or log of mean test weight) for treatment $j$ in study $i$, and the sampling variance $\left(s_{i j}^{2}\right)$ is a function of both the mean square error and the mean yield (or test weight) for treatment $j$ of study $i$ (see page 1,001 in Paul et al. [33]). Because a percentage change involves a ratio, a percent-change analysis should best be based on the $\log$ of the response variables in order to meet certain statistical requirements $(8,32)$. The mean effect size (i.e., difference of logs) directly calculated from this meta-analysis is equal to the $\log$ of the response ratio (33). We obtained the estimated increase in mean yield (or test weight) due to the fungicide treatment $(\bar{I})$ based on algebraic manipulation of the antilog of the log response ratio, using the same general approach found in Paul et al. (33).

\section{RESULTS}

FHB, grain yield, test weight, and overall fungicide effects. FHB intensity, grain yield, and test weight varied among studies and among treatments within studies. Mean FHB index was 0 to $55 \%$ in soft-red winter-wheat studies and 0 to $51 \%$ in springwheat studies (Fig. 1A), reflecting differences in weather conditions among years and locations, differences in cultivar susceptibility to FHB, and differences in fungicide efficacy against FHB in both wheat types. The range (difference between maximum and minimum) for mean index for the untreated check was $51 \%$ in spring wheat and $55 \%$ in soft-red winter wheat, compared with 42 and $37 \%$, respectively, for the two wheat types for fungicidetreated plots. Averaged across all treatments and studies in each wheat type, mean index was $2 \%$ higher in spring-wheat than in winter-wheat studies; mean grain yield was $791 \mathrm{~kg} / \mathrm{ha}$ higher in winter wheat than in spring wheat; and mean test weight was $38 \mathrm{~kg} / \mathrm{m}^{3}$ higher in spring wheat than in winter wheat. Based on treatment means, yields were 1,419 to $6,504 \mathrm{~kg} / \mathrm{ha}$ in spring wheat and 1,118 to $7,512 \mathrm{~kg} / \mathrm{ha}$ in winter wheat (Fig. 1B); whereas test weights were 534 to 817 and 342 to $850 \mathrm{~kg} / \mathrm{m}^{3}$ in springand winter-wheat studies, respectively (Fig. 1C). For the untreated check, mean yield was 1,419 to $6,108 \mathrm{~kg} / \mathrm{ha}$ in spring wheat and 1,118 to $7,344 \mathrm{~kg} / \mathrm{ha}$ in soft-red winter wheat; for the fungicidetreated plots, yields were 1,419 to $6,504 \mathrm{~kg} / \mathrm{ha}$ in spring wheat and 1,344 to $7,512 \mathrm{~kg} / \mathrm{ha}$ in winter wheat. Correspondingly, for spring and winter wheat, mean test weights were 534 to 804 and 342 to $828 \mathrm{~kg} / \mathrm{m}^{3}$, respectively, for the untreated check and 556 to 817 and 367 to $850 \mathrm{~kg} / \mathrm{m}^{3}$, respectively, for fungicide-treated plots.

The difference in mean yields and test weights between treated and check plots $\left(D=\bar{X}_{\text {Treated }}-\bar{X}_{\text {Check }}\right)$ in individual studies varied for all tested fungicides. The range of $D$ for yield and test weight was $1,794 \mathrm{~kg} / \mathrm{ha}$ and $104 \mathrm{~kg} / \mathrm{m}^{3}$ for TEBU (Fig. 2A and B), $1,717 \mathrm{~kg} / \mathrm{ha}$ and $88 \mathrm{~kg} / \mathrm{m}^{3}$ for PROP (Fig. 2C and D), 1,794 kg/ha and $106 \mathrm{~kg} / \mathrm{m}^{3}$ for PROT (Fig. 2E and F), 1,978 kg/ha and $158 \mathrm{~kg} / \mathrm{m}^{3}$ for TEBU+PROT (Fig. $2 \mathrm{G}$ and $\mathrm{H}$ ), and $2,213 \mathrm{~kg} / \mathrm{ha}$ and $176 \mathrm{~kg} / \mathrm{m}^{3}$ for METC (Fig. 2I and J). Fungicide-treated plots generally out-yielded and had higher test weight than the untreated check; however, treated plots had numerically lower means than the check in 11 to $19 \%$ of the studies for yield and 16 to $37 \%$ of the studies for test weight (Fig. 2). For both yield and test weight, TEBU and PROP were the treatments with the highest number of negative responses.

Meta-analysis. The effects of the fungicides tested in this study on grain yield and test weight were evaluated on the basis of the magnitude and significance of the mean difference between each treatment and the untreated check. Based on the standard normal test statistic from the meta-analysis, the overall mean difference (the effect size $[\bar{D}]$ ), was positive and significantly different
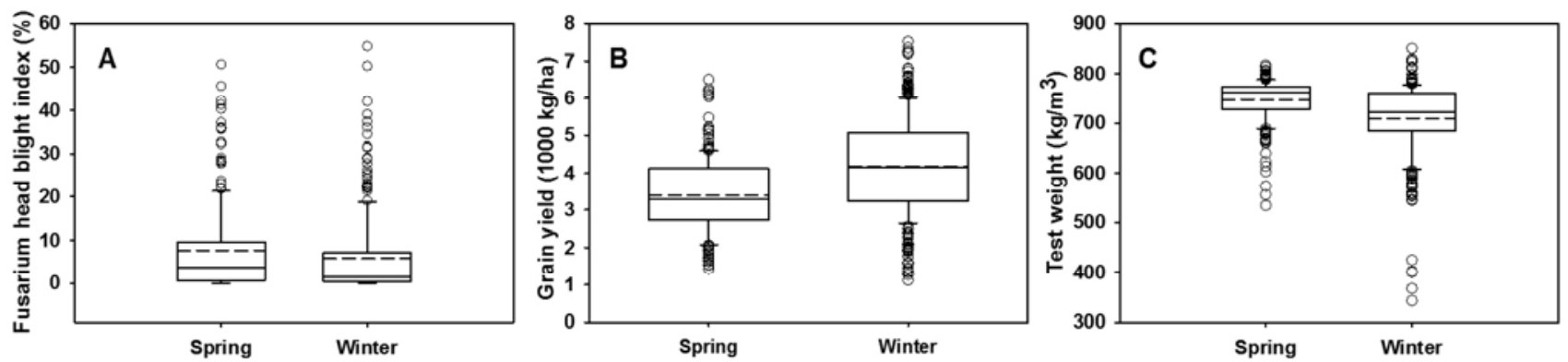

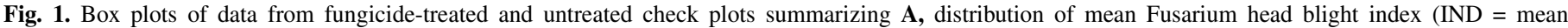

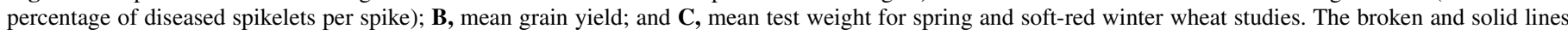

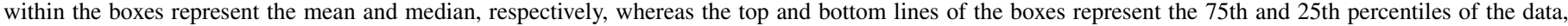

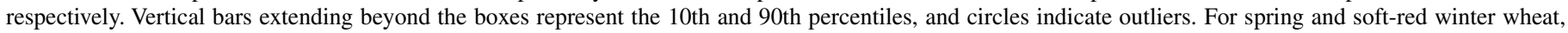
$N=239$ and 295 for IND, 239 and 319 for yield, and 234 and 267 for test weight, respectively. 
from zero for both yield and test weight for all tested fungicides $(P<0.05)$ (Table 1). For yield, $\bar{D}$ was highest for metconazole $(450 \mathrm{~kg} / \mathrm{ha})$ and tebuconazole+prothioconazole $(445 \mathrm{~kg} / \mathrm{ha})$ and lowest for tebuconazole (273 kg/ha) and propiconazole (200 kg/ha). Similarly, for test weight, $\bar{D}$ was highest for metconazole $\left(19 \mathrm{~kg} / \mathrm{m}^{3}\right)$ and lowest for propiconazole $\left(5 \mathrm{~kg} / \mathrm{m}^{3}\right)$.
The percent increase in yield was much higher than the percent increase in test weight (Table 1). Tebuconazole, propiconazole, prothioconazole, tebuconazole+prothioconazole, and metconazole led to an estimated $9.4,6.8,13.8,14.5$, and $15.0 \%$ increase, respectively, in yield, and only a 1.4, 0.7, 2.5, 2.5, and $2.8 \%$ increase in test weight. For both yield and test weight, the width
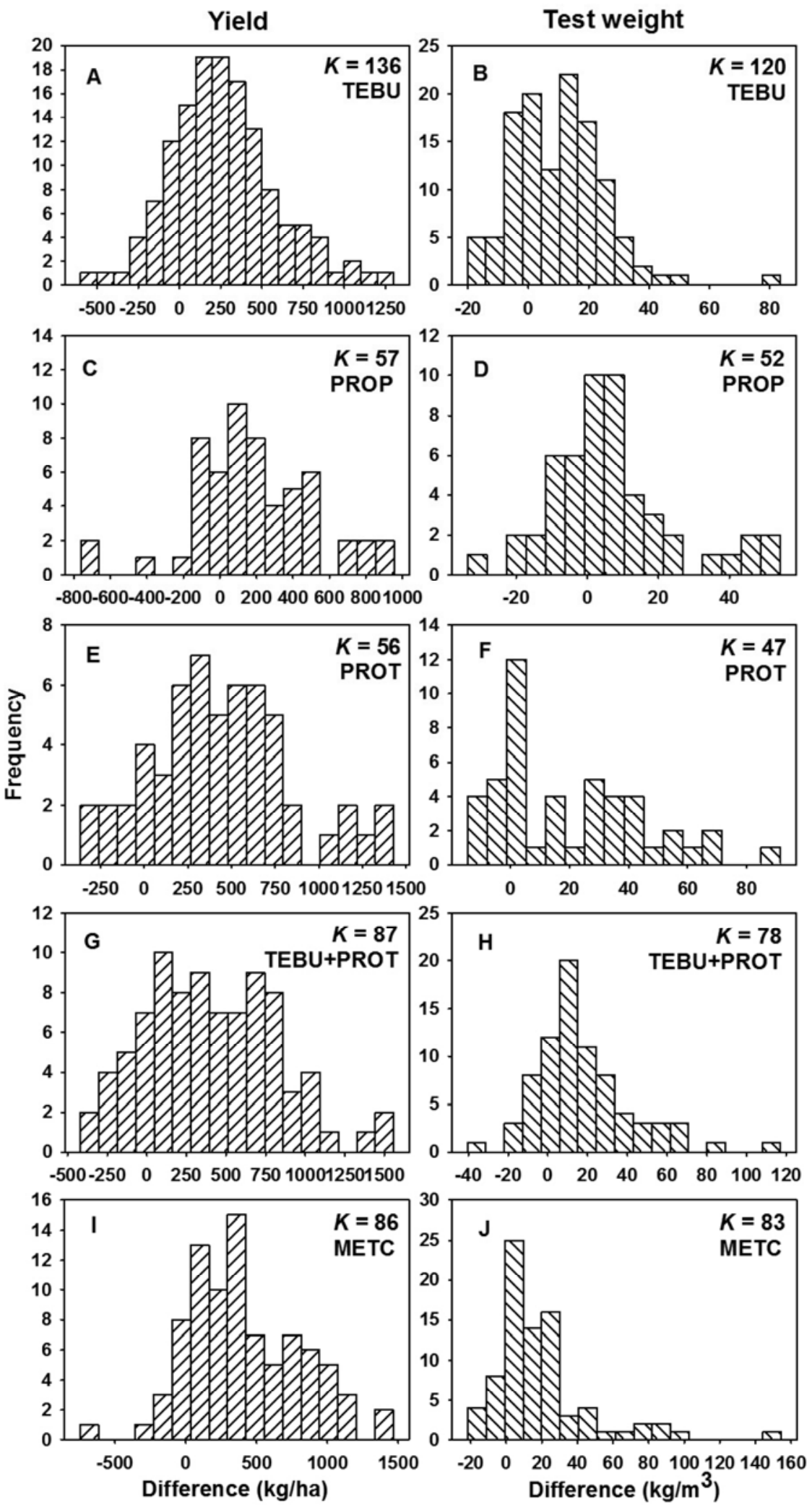

Fig. 2. Frequency distribution of mean difference in wheat grain yield and test weight relative to the untreated check for $\mathbf{A}$ and $\mathbf{B}$, tebuconazole (TEBU); $\mathbf{C}$ and $\mathbf{D}$, propiconazole (PROP); $\mathbf{E}$ and $\mathbf{F}$, prothioconazole (PROT); $\mathbf{G}$ and $\mathbf{H}$, a mixture of tebuconazole and prothioconazole (TEBU+PROT); and I and $\mathbf{J}$, metconazole (METC) applied at anthesis for Fusarium head blight management. $K$ is the number of studies in which the indicated variable was measured. 
of the $95 \%$ confidence interval around $\bar{D}$ was narrowest for tebuconazole. On the other hand, tebuconazole+prothioconazole had the widest confidence interval for yield and metconazole the widest interval for test weight. The width of the confidence intervals reflect, in part, the number of studies in the analysis; with yield, for instance, there were 49 more studies with the tebuconazole treatment than the tebuconazole+prothioconazole treatment.

A likelihood-ratio test for both yield and test weight indicated that the meta-analysis model with random effects of study on the treatment effects (equation 1) fitted the data significantly better than a fixed-effects model (a model with no among-study variances or covariances) $(P<0.001)$. The $R^{2}$ statistics $(13)$ were $>3.0$ for all mean effect sizes in Table 1. Higgins et al. (13) indicated that values of $R^{2}>1.5$ indicate considerable ("influential") heterogeneity. Thus, all presented results are based on metaanalytical models with nonzero random effects.

Influence of moderator variables on yield and test weight responses to fungicides. For all but one of the tested fungicides, tebuconazole+prothioconazole, wheat type had a significant effect on $\bar{D}$ for yield, based on the $\chi^{2}$ test statistics $(P<0.05)$ (Table 2). $\bar{D}$ was significantly higher for spring than soft-red winter

TABLE 1. Effect sizes and corresponding statistics, and percent increase for the effect of triazole-based fungicides on wheat grain yield and test weight

\begin{tabular}{|c|c|c|c|c|c|c|c|c|}
\hline \multirow[b]{2}{*}{ Response, fungicide ${ }^{a}$} & \multirow[b]{2}{*}{$K^{\mathrm{b}}$} & \multicolumn{6}{|c|}{ Statistics $^{\mathrm{c}}$} & \multirow[b]{2}{*}{$\bar{I}^{\mathrm{d}}$} \\
\hline & & $\bar{D}$ & $\operatorname{se}(\bar{D})$ & $C I_{L}$ & $C I_{U}$ & $Z$ & $P$ & \\
\hline \multicolumn{9}{|l|}{ Yield } \\
\hline TEBU & 136 & $272.6(4.3)$ & 25.09 & 223.4 & 321.8 & 10.9 & $<0.001$ & 9.44 \\
\hline PROP & 57 & $199.6(3.2)$ & 32.16 & 136.5 & 262.7 & 6.2 & $<0.001$ & 6.78 \\
\hline PROT & 56 & $419.1(6.7)$ & 37.32 & 345.8 & 492.3 & 11.2 & $<0.001$ & 13.75 \\
\hline TEBU+PROT & 87 & $444.5(7.1)$ & 38.40 & 369.2 & 519.9 & 11.6 & $<0.001$ & 14.52 \\
\hline METC & 86 & $450.4(7.2)$ & 33.10 & 385.5 & 515.4 & 13.6 & $<0.001$ & 14.97 \\
\hline \multicolumn{9}{|l|}{ Test weight } \\
\hline TEBU & 120 & $9.6(0.7)$ & 1.21 & 7.2 & 12.0 & 7.9 & $<0.001$ & 1.39 \\
\hline PROP & 52 & $5.0(0.4)$ & 1.44 & 2.2 & 7.8 & 3.5 & $<0.001$ & 0.71 \\
\hline PROT & 47 & $17.4(1.3)$ & 2.13 & 13.2 & 21.6 & 8.1 & $<0.001$ & 2.53 \\
\hline TEBU+PROT & 78 & $17.4(1.3)$ & 1.85 & 13.7 & 21.0 & 9.4 & $<0.001$ & 2.52 \\
\hline METC & 83 & $19.4(1.5)$ & 2.61 & 14.3 & 24.6 & 7.4 & $<0.001$ & 2.82 \\
\hline
\end{tabular}

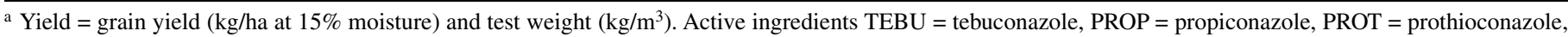
and $\mathrm{METC}=$ metconazole .

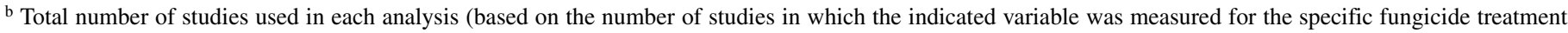
and the control).

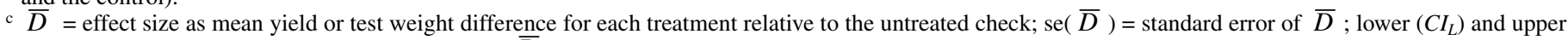
$\left(C I_{U}\right)$ limits of the $95 \%$ confidence interval around $\bar{D}$; and $Z$ (standard normal) statistic from the meta-analysis. $P=$ probability value (significance level) for the effect of treatment on the effect size. In parentheses, yield converted to bushels/acre and test weight converted to pounds/bushel.

${ }^{\mathrm{d}}$ Mean percent yield and test weight increase.

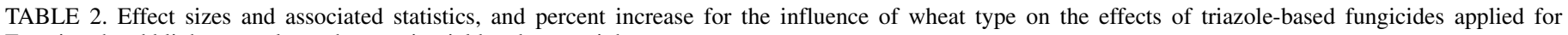
Fusarium head blight control on wheat grain yield and test weight

\begin{tabular}{|c|c|c|c|c|c|c|c|c|}
\hline \multirow[b]{2}{*}{ Response, fungicide $^{a}$} & \multirow[b]{2}{*}{ Type $^{\text {b }}$} & \multirow[b]{2}{*}{$K^{\mathrm{c}}$} & \multicolumn{5}{|c|}{ Statistics $^{\mathrm{d}}$} & \multirow[b]{2}{*}{$\bar{I}^{\mathrm{e}}$} \\
\hline & & & $\bar{D}$ & $\operatorname{se}(\bar{D})$ & $C I_{L}$ & $C I_{U}$ & $P$ & \\
\hline \multicolumn{9}{|l|}{ Yield } \\
\hline \multirow[t]{2}{*}{ TEBU } & Spring & 58 & $338.9(5.4)$ & 35.24 & 269.7 & 408.0 & 0.011 & 12.64 \\
\hline & Winter & 78 & $213.2(3.4)$ & 34.40 & 145.7 & 280.7 & $\ldots$ & 6.87 \\
\hline \multirow[t]{2}{*}{ PROP } & Spring & 27 & $264.5(4.2)$ & 44.10 & 178.0 & 351.1 & 0.047 & 9.23 \\
\hline & Winter & 30 & $137.5(2.2)$ & 45.96 & 47.4 & 227.7 & $\ldots$ & 4.35 \\
\hline \multirow[t]{2}{*}{ PROT } & Spring & 19 & $504.8(8.0)$ & 56.19 & 394.5 & 615.1 & 0.041 & 17.97 \\
\hline & Winter & 37 & $351.5(5.6)$ & 49.32 & 254.7 & 448.3 & $\ldots$ & 10.66 \\
\hline \multirow[t]{2}{*}{ TEBU+PROT } & Spring & 37 & $509.5(8.1)$ & 56.52 & 398.6 & 620.4 & 0.153 & 18.31 \\
\hline & Winter & 50 & $399.5(6.4)$ & 52.21 & 297.0 & 501.9 & $\ldots$ & 11.84 \\
\hline \multirow[t]{2}{*}{ METC } & Spring & 40 & $536.2(8.5)$ & 46.86 & 444.3 & 628.2 & 0.012 & 19.32 \\
\hline & Winter & 46 & 372.5 (5.9) & 45.40 & 283.4 & 461.6 & $\ldots$ & 11.49 \\
\hline \multicolumn{9}{|l|}{ Test weight } \\
\hline \multirow[t]{2}{*}{ TEBU } & Spring & 57 & $10.6(0.8)$ & 1.73 & 7.2 & 14.0 & 0.433 & 1.47 \\
\hline & Winter & 63 & $8.7(0.7)$ & 1.71 & 5.3 & 12.0 & $\ldots$ & 1.33 \\
\hline \multirow[t]{2}{*}{ PROP } & Spring & 26 & $8.0(0.6)$ & 2.01 & 4.0 & 11.9 & 0.058 & 1.08 \\
\hline & Winter & 26 & $2.6(0.2)$ & 2.02 & -1.4 & 6.5 & $\ldots$ & 0.43 \\
\hline \multirow[t]{2}{*}{ PROT } & Spring & 18 & $20.2(1.6)$ & 3.09 & 14.1 & 26.3 & 0.261 & 2.81 \\
\hline & Winter & 29 & $15.4(1.2)$ & 2.92 & 9.7 & 21.2 & $\ldots$ & 2.37 \\
\hline \multirow[t]{2}{*}{ TEBU+PROT } & Spring & 36 & $20.2(1.6)$ & 2.64 & 15.0 & 25.3 & 0.170 & 2.80 \\
\hline & Winter & 42 & $15.1(1.2)$ & 2.54 & 10.1 & 20.1 & $\ldots$ & 2.32 \\
\hline \multirow[t]{2}{*}{ METC } & Spring & 40 & $21.4(1.7)$ & 3.72 & 14.1 & 28.7 & 0.510 & 2.98 \\
\hline & Winter & 43 & $18.0(1.4)$ & 3.63 & 10.9 & 25.1 & $\ldots$ & 2.73 \\
\hline
\end{tabular}

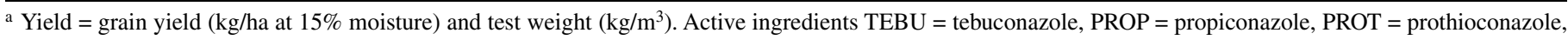
and METC = metconazole.

b Data obtained from winter wheat and spring wheat studies.

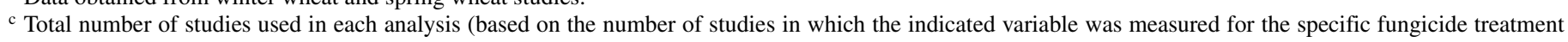
and the control).

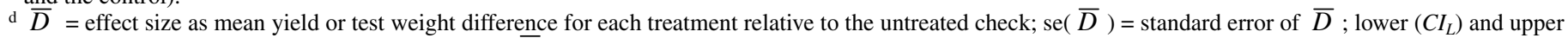
$\left(C I_{U}\right)$ limits of the $95 \%$ confidence interval around $\bar{D}$; and $Z$ (standard normal) statistic from the meta-analysis. $P=$ probability value (significance level) for the effect of wheat type on the effect of treatment on yield or test weight. In parentheses, yield converted to bushels/acre and test weight converted to pounds/bushel.

e Mean percent yield and test weight increase. 
wheat, with differences between the two wheat types of 126, 127, 154 , and $163 \mathrm{~kg} / \mathrm{ha}$ for tebuconazole, propiconazole, prothioconazole, and metconazole, respectively. Metconazole, tebuconazole+ prothioconazole, and prothioconazole resulted in the highest yield increase relative to the untreated check in spring wheat, whereas tebuconazole+prothioconazole, followed by metconazole and prothioconazole, resulted in the highest yield increase in soft-red winter wheat. Depending on the fungicide, mean percent yield increase ranged from 9.2 (propiconazole) to $19.3 \%$ (metconazole) for spring wheat and from 4.4 (propiconazole) to $11.8 \%$ (tebuconazole+prothioconazole) for soft-red winter wheat (Table 2).

In contrast, although $\bar{D}$ values for test weight were numerically higher for spring than for soft winter wheat, the effect of wheat type on test weight was not statistically significant for any of the tested fungicides $(P>0.05)$ (Table 2$)$. Only with propiconazole was wheat type marginally significant $(P \approx 0.06)$.

The $\chi^{2}$ test statistics from the meta-analysis indicated that FHB index in the check (baseline disease index or baseline disease risk) had a statistically significant $(P<0.05)$ effect on yield and test weight responses to fungicide treatment. Based on the estimates of $t_{j}$ in equation 3 , the magnitude of the mean difference between treated and nontreated plots depended on disease index. Estimates of $\imath_{j}$ were $-18.63,-18.56,-12.25,-10.52,-10.56$, and -22.85 for tebuconazole, propiconazole, prothioconazole, tebuconazole+prothioconazole, metconazole, and the check, respectively. This means that for every unit increase in baseline disease index (e.g., 10 to $11 \%$ ), $\bar{D}$ was predicted to increase by 4.22 $(=-18.63-[-22.85]), 4.29,10.6,12.3$, and $12.3 \mathrm{~kg} / \mathrm{ha}$. For all fungicides, yield decreased and the magnitude of $\bar{D}$ increased with increasing FHB index in the check. Results were based on the fit of equation 2, with both wheat type and baseline disease index in the model. The same general trends observed when the effects of wheat class on $\bar{D}$ were evaluated across all levels of FHB (Table 2) were also observed at specific levels of FHB index. For exposition purposes, effects at baseline index values of 5 and $30 \%$ were calculated (Table 3 ). In particular, the effect of wheat type on $\bar{D}$ for yield was statistically significant $(P<0.05)$ for all fungicides except tebuconazole+prothioconazole at the two example baseline index values (Table 3 ). At both levels of baseline disease index, $\bar{D}$ was significantly higher for spring wheat than for soft-red winter wheat with the tebuconazole, propiconazole, prothioconazole, and metconazole treatments.

At $30 \%$ disease index, percent increase in yield $(\bar{I})$ was 11.4 to $28.7 \%$ for spring wheat and 6.5 to $21.6 \%$ for soft-red winter wheat; whereas, at $5 \%$ disease index, $\bar{I}$ was substantially lower for all fungicides in both wheat types ( 8 to $15 \%$ for spring wheat and 3 to $8 \%$ for soft winter wheat) (Table 3). As found when baseline disease index was not considered, metconazole, tebuconazole+prothioconazole, and prothioconazole were the most effective fungicide treatments for yield response at the different tested baseline index values (Table 3 ).

Propiconazole was the only fungicide for which wheat type had a significant effect on test weight $(P<0.05)$ (Table 4$)$ at either level of the evaluated baseline index values. As with yield, test weight decreased and $\bar{D}$ increased as baseline index increased. Estimates of $\mathrm{l}_{j}$ for test weight were $-2.18,-2.64,-1.67,-1.85$, -1.85 , and -2.62 for tebuconazole, propiconazole, prothioconazole, tebuconazole+prothioconazole, metconazole, and the check, respectively, meaning that, for every unit increase in baseline disease index, $\bar{D}$ for test weight was predicted to increase by

TABLE 3. Effect sizes and associated statistics, and percent increase for the influence of wheat type and mean Fusarium head blight intensity in the untreated check on the effects of triazole-based fungicides on wheat grain yield

\begin{tabular}{|c|c|c|c|c|c|c|c|c|}
\hline \multirow[b]{2}{*}{ Baseline, fungicide ${ }^{a}$} & \multirow[b]{2}{*}{ Type $^{b}$} & \multirow[b]{2}{*}{$K^{\mathrm{c}}$} & \multicolumn{5}{|c|}{ Effect size $^{\mathrm{d}}$} & \multirow[b]{2}{*}{$\bar{I}^{\mathrm{e}}$} \\
\hline & & & $\bar{D}$ & $\operatorname{se}(\bar{D})$ & $C I_{L}$ & $C I_{U}$ & $P$ & \\
\hline \multicolumn{9}{|l|}{$\overline{\text { IND5 }}$} \\
\hline TEBU & Spring & 58 & $302.7(4.8)$ & 36.66 & 230.8 & 374.7 & 0.003 & 10.59 \\
\hline \multirow[t]{2}{*}{ PROP } & Spring & 27 & $224.0(3.6)$ & 44.75 & 136.2 & 311.8 & 0.035 & 7.76 \\
\hline & Winter & 30 & $91.6(1.5)$ & 45.91 & 1.6 & 181.7 & & 2.96 \\
\hline PROT & Spring & 19 & $414.0(6.6)$ & 51.42 & 313.1 & 514.9 & 0.021 & 13.62 \\
\hline TEBU+PROT & Winter & 50 & $297.4(4.7)$ & 48.31 & 202.6 & 392.2 & & 8.12 \\
\hline \multirow[t]{2}{*}{ METC } & Spring & 40 & $430.1(6.9)$ & 38.10 & 355.3 & 504.9 & 0.003 & 14.36 \\
\hline & Winter & 46 & 273.5 & 38.42 & 198.1 & 348.8 & $\ldots$ & 8.08 \\
\hline \multicolumn{9}{|l|}{ IND30 } \\
\hline \multirow[t]{2}{*}{ TEBU } & Spring & 58 & $408.1(6.5)$ & 45.38 & 319.1 & 497.2 & 0.003 & 15.82 \\
\hline & Winter & 78 & $264.5(4.2)$ & 52.36 & 161.7 & 367.2 & 0.00 & 9.84 \\
\hline PROP & Spring & 27 & $331.2(5.3)$ & 78.59 & 177.0 & 485.4 & 0.035 & 11.42 \\
\hline \multirow[t]{2}{*}{ METC } & Spring & 40 & $737.4(11.7)$ & 48.84 & 641.5 & 833.2 & 0.003 & 28.67 \\
\hline & Winter & 46 & $580.7(9.3)$ & 55.35 & 472.1 & 689.3 & $\ldots$ & 21.60 \\
\hline \multicolumn{9}{|c|}{$\begin{array}{l}\text { Fusarium head blight index (mean proportion of diseased spikelets per spike) of } 5 \text { and } 30 \% \text { (IND5 and IND30, respectively) in the untreated check as baseline } \\
\text { values from a multivariate meta-analysis in which mean disease index in the check was used a continuous moderator or predictor of the effect of fungicides used } \\
\text { for Fusarium head blight control on wheat grain yield. Active ingredients TEBU = tebuconazole, PROP = propiconazole, PROT = prothioconazole, and METC }= \\
\text { metconazole. } \\
\text { b Data obtained from winter wheat and spring wheat studies. } \\
\text { c Total number of studies used in each analysis (based on the number of studies in which the indicated variable was measured for the specific fungicide treatment } \\
\text { and the control). } \\
\text { d } \bar{D}=\text { effect size as mean yield }\left(\mathrm{kg} / \mathrm{ha} \text { ) or test weight }\left(\mathrm{kg} / \mathrm{m}^{3}\right) \text { difference for each treatment relative to the untreated check; se }(\bar{D})=\mathrm{standard} \text { error of } \bar{D} ; \text { lower }\right. \\
\left(C I_{L}\right) \text { and upper }\left(C I_{U}\right) \text { limits of the } 95 \% \text { confidence interval around } \bar{D} ; \text { and } Z \text { (standard normal) statistic from the meta-analysis. } P=\text { probability value } \\
(\text { significance level) for the effect of wheat type on the treatment effect on yield (at the selected baseline disease index). For each active ingredient and wheat type, } \\
\text { the effect size, } \bar{D} \text {, was estimated for fixed baseline index levels }(5 \text { and } 30 \% \text { IND) and not for separate subsets of the studies with these index levels. Because } \\
\text { index was used as a continuous moderator variable, this process was somewhat analogous to using analysis of covariance in a hierarchical model (19) to estimate } \\
\text { the mean effect size from mean disease index. In parentheses, yield converted to bushels/acre. }\end{array}$} \\
\hline
\end{tabular}


$0.44 \mathrm{~kg} / \mathrm{m}^{3}(=-2.18-[-2.62])$ for tebuconazole, $0.96 \mathrm{~kg} / \mathrm{m}^{3}$ for prothioconazole, $0.77 \mathrm{~kg} / \mathrm{m}^{3}$ tebuconazole+prothioconazole, and $0.78 \mathrm{~kg} / \mathrm{m}^{3}$ for metconazole. Mean percent increase in test weight ( $\bar{I}$ ) was considerably lower than for yield, with $\bar{I}$ of 0.2 to $5.5 \%$ at $30 \%$ disease index and 0.1 to $2.3 \%$ at $5 \%$ disease index.

Risk analysis. Because of the significant effects of wheat type and baseline disease index, the probabilities of wheat yield exceeding specified constants $\left(p_{+}, p_{250}\right.$, and $\left.p_{500}\right)$ in a randomly selected study were estimated separately for the two wheat types and two example levels of the baseline index (5 and 30\%). At the higher baseline disease index $(30 \%)$, the probability of a positive yield increase for a fungicide treatment relative to the check $\left(p_{+}\right)$ was very high for both spring and soft-red winter wheat $(>0.99$ for the best treatments) (Table 5). At a lower disease index (5\%), $p_{+}$was still $>0.90$ for spring wheat for all treatments but somewhat lower for winter wheat. For instance, at this lower disease index, the probability of a positive yield increase for the tebuconazole treatment in a randomly selected study was 0.95 for spring and 0.80 for soft-red winter wheat.

By definition, the probability of a yield increase exceeding certain cut-off constants in a randomly selected study declined as the cut-off increased (i.e., from 0 to 250 to $500 \mathrm{~kg} / \mathrm{ha}$ ) (Table 5). Nevertheless, for the three best fungicide treatments (prothioconazole, tebuconazole+prothioconazole, and metconazole) at the higher baseline disease index $(B=30 \%), p_{250}$ was $\geq 0.95$ for spring wheat and $\geq 0.90$ for soft-red winter wheat. However, $p_{250}$ was considerably lower for the other two fungicides, especially with winter wheat; for example, $p_{250}$ at $30 \%$ index was only 0.53 for tebuconazole with soft-red winter wheat. At the lower baseline disease index $(5 \%)$, there was a considerable reduction in the $p_{250}$ values. The three best fungicide treatments had $p_{250}$ values of 0.71 to 0.86 for spring wheat and 0.51 to 0.57 for soft-red winter wheat. For instance, with $p_{250}=0.51$, there was only a 50:50 chance that soft-red winter wheat treated with prothioconazole would have an increase in yield of $\geq 250 \mathrm{~kg} / \mathrm{ha}$ relative to the untreated check. The other two fungicide treatments had much lower $p_{250}$ values for both spring and winter wheat.

At $30 \%$ baseline disease index, $p_{500}$ was $>0.9$ only for the metconazole treatment applied to spring wheat (Table 5). This fungicide treatment also gave the highest $p_{500}$ value for soft-red winter wheat but the probability was only 0.68 . At $5 \%$ disease index, the three best fungicide treatments had $p_{500}$ values of 0.34 to 0.35 for spring wheat and $<0.25$ for soft-red winter wheat.

\section{DISCUSSION}

Based on data from numerous studies conducted according to standard protocols, the results presented herein constitute the first comprehensive quantitative synthesis of wheat grain yield and test weight responses across a wide range of environments to the most effective fungicides against FHB. Previous published reports on FHB fungicide treatment effects on yield and test weight were based on individual or small numbers of studies, and did not necessarily include products that are now known to be the most effective active ingredients against FHB and DON $(14,15,23,28)$. Through a multivariate random-effects meta-analyses of data from $>100$ uniform fungicide trials, the overall mean effects of tebuconazole, propiconazole, prothioconazole, tebuconazole+ prothioconazole, and metconazole on yield and test weight were determined based on the mean differences between treated and

TABLE 4. Effect sizes and associated statistics, and percent increase for the influence of wheat type and mean Fusarium head blight intensity in the untreated check on the effects of triazole-based fungicides on wheat test weight

\begin{tabular}{|c|c|c|c|c|c|c|c|c|}
\hline \multirow[b]{2}{*}{ Baseline, fungicide ${ }^{a}$} & \multirow[b]{2}{*}{ Type $^{\mathrm{b}}$} & \multirow[b]{2}{*}{$K^{\mathrm{c}}$} & \multicolumn{5}{|c|}{ Effect size $^{\mathrm{d}}$} & \multirow[b]{2}{*}{$\bar{I}^{\mathrm{e}}$} \\
\hline & & & $\bar{D}$ & $\operatorname{se}(\bar{D})$ & $C I_{L}$ & $C I_{U}$ & $P$ & \\
\hline \multicolumn{9}{|l|}{ IND5 } \\
\hline \multirow[t]{2}{*}{ PROP } & Spring & 26 & $6.7(0.5)$ & 2.24 & 2.3 & 11.1 & 0.048 & 0.87 \\
\hline & Winter & 26 & $0.5(<0.1)$ & 2.24 & -3.9 & 4.9 & & 0.12 \\
\hline PROT & Spring & 18 & 13.4 (1.0) & 2.84 & 7.8 & 19.0 & 0.398 & 1.75 \\
\hline TEBU+PROT & Winter & 42 & $11.8(0.9)$ & 2.36 & 7.2 & 16.4 & $\ldots$ & 1.80 \\
\hline \multirow[t]{2}{*}{ METC } & Spring & 40 & $15.3(1.2)$ & 3.81 & 7.8 & 22.7 & 0.984 & 1.99 \\
\hline & Winter & 43 & $15.2(1.2)$ & 3.53 & 8.2 & 22.1 & $\ldots$ & 2.26 \\
\hline \multicolumn{9}{|l|}{ IND30 } \\
\hline \multirow[t]{2}{*}{ TEBU } & Spring & 57 & $18.0(1.4)$ & 2.41 & 13.3 & 22.8 & 0.798 & 2.64 \\
\hline & Winter & 64 & $17.4(1.4)$ & 2.93 & 11.7 & 23.1 & & 2.69 \\
\hline PROP & Spring & 26 & $6.3(0.5)$ & 3.74 & -1.0 & 13.6 & 0.048 & 0.97 \\
\hline \multirow{2}{*}{ METC } & Spring & 40 & 34.7 (2.7) & 5.17 & 24.5 & 44.8 & 0.984 & 5.18 \\
\hline & Winter & 43 & $34.6(2.7)$ & 5.98 & 22.8 & 46.3 & $\ldots$ & 5.47 \\
\hline
\end{tabular}

${ }^{a}$ Fusarium head blight index (mean proportion of diseased spikelets per spike) of 5 and 30\% (IND5 and IND30, respectively) in the untreated check as baseline values from a multivariate meta-analysis in which mean disease index in the check was used a continuous moderator or predictor of the effect of fungicides used for Fusarium head blight control on wheat test weight. Active ingredients TEBU $=$ tebuconazole, $\mathrm{PROP}=$ propiconazole, $\mathrm{PROT}=$ prothioconazole, and $\mathrm{METC}=$ metconazole.

${ }^{\mathrm{b}}$ Data obtained from winter wheat and spring wheat studies.

c Total number of studies used in each analysis (based on the number of studies in which the indicated variable was measured for the specific fungicide treatment and the control).

d $\bar{D}=$ effect size as mean yield $(\mathrm{kg} / \mathrm{ha})$ or test weight $\left(\mathrm{kg} / \mathrm{m}^{3}\right)$ difference for each treatment relative to the untreated check; $\operatorname{se}(\bar{D})=\operatorname{standard}$ error of $\bar{D} ;$ lower $\left(C I_{L}\right)$ and upper $\left(C I_{U}\right)$ limits of the $95 \%$ confidence interval around $\bar{D}$; and $Z$ (standard normal) statistic from the meta-analysis. $P=$ probability value (significance level) for the effect of wheat type on the treatment effect on test weight (at the selected baseline disease index). For each active ingredient and wheat type, the effect size, $\bar{D}$, was estimated for fixed baseline index levels (5 and 30\% IND) and not for separate subsets of the studies with these index levels. Because index was used as a continuous moderator variable, this process was somewhat analogous to using analysis of covariance in a hierarchical model (19) to estimate the mean effect size from mean disease index. In parentheses, test weight converted to pounds/bushel.

e Mean percent test weight increase/decrease. 
nontreated plots ( $\bar{D}$, the effect size). All five fungicides led to a significant overall increase in both mean yield and mean test weight relative to the check (Table 1). For most fungicides, mean effect sizes were significantly higher in spring wheat than in softred winter wheat, and effect sizes increased significantly with baseline disease index for both wheat types. Tebuconazole+ prothioconazole was the only fungicide for which the effect of wheat type was not statistically significant, suggesting consistency in yield response to this product in both spring and soft winter wheat (Table 2). However, this lack of significance (at the $5 \%$ level of probability) may be partly due to the fact that the effect of this fungicide on yield was the most variable, based on the width of the $95 \%$ confidence interval around $\bar{D}$ (Tables 1 and 2). Like yield, test weight was also significantly affected by treatment; however, the percent increase in test weight in a treatment relative to the untreated check (overall, 0.7 to $2.8 \%$ ) was much smaller than the percent increase in yield (6.8 to $15.0 \%$ ) (Table 1). Furthermore, wheat type only affected test weight increase with one treatment. Thus, as a reasonable approximation, test weight can be considered constant for these studies.

The rankings of treatment effectiveness from these metaanalysis of yield (and test weight) were fairly consistent with the rankings from previous meta-analyses of FHB disease index in field plots and DON in harvested grain from these field plots, based on a subset (pre-2006) of the dataset used here (33). That is, metconazole, tebuconazole+prothioconazole, and prothioconazole were also the most effective fungicides at reducing FHB and DON and, for all three products, efficacy was significantly greater in spring wheat than in soft-red winter wheat. This suggests that the observed mean yield increase $(\bar{D})$ may be attributed, at least in part, to the magnitude of FHB reduction ( $\bar{C}_{I N D}$ in field plots) (33). Our results corroborate the results of other studies where the treatment or treatment combinations that resulted in the greatest reduction in FHB led to the highest increase in yield and test weight $(14,15,28)$. FHB directly impacts grain yield by causing premature death of spikelets or entire spikes, which leads to the development of shriveled, small, light-weight kernels and fewer kernels per spike $(15,31,37)$. During infection, the fungus spreads from spikelet to spikelet through the rachis, impeding the movement of nutrients through the vascular system to the developing grain. This results in lower overall test weight and grain produc- tion per unit area. Hence, yield and test weight reduction tend to be associated with the level of FHB reduction.

Madden and Paul (22) used random-coefficient mixed models to evaluate the relationship between FHB index and grain yield in field plots based on a subset of the studies used in this investigation (utilizing only studies that had sufficient range of FHB values to reasonably characterize how yield declines with increasing FHB within studies). They found a straight-line relationship between disease and yield (kg/ha), with an estimated "populationaverage" disease-free yield that depended on wheat type $(4,570 \mathrm{~kg} / \mathrm{ha}$ for soft-red winter and $3,720 \mathrm{~kg} / \mathrm{ha}$ for spring wheat), and an estimated population-average slope of $37 \mathrm{~kg} / \mathrm{ha}$ per unit increase in FHB (with disease index measured on a percentage scale at Feekes' GS 11.2) that was invariant to wheat type. A straight-line relationship on a percentage yield scale was also found by Willocquet et al. (46) using published wheat-FHB data from Hungary. Although fungicide treatment was not analyzed or considered in the model development in Madden and Paul (22), based on the estimated parameters in their investigation, they predicted, on average, that (i) the expected percent increase in yield $(\bar{I})$ would be less than the percent reduction in FHB (percent control, $\bar{C}_{I N D}$ ); (ii) $\bar{I}$ would increase with $\bar{C}_{I N D}$ (meaning that, all other things being equal, increasing efficacy for disease control would translate to increasing efficacy for yield increase); (iii) $\bar{I}$ would depend on the level of FHB index in the check, with $\bar{I}$ increasing as FHB index increased; and (iv) $\bar{I}$ would increase with decreasing level of the disease-free yield (which would mean that $\bar{I}$ would be higher for spring than for soft-red winter wheat at a given value of $\bar{C}_{I N D}$ ). All of these predictions were supported by the treatment-effect results of this investigation based on an analysis of a larger population of studies. For instance, Paul et al. (33) (Table 3) found that $\bar{C}_{I N D}$ was 32 and $42 \%$ for soft-red winter wheat treated with tebuconazole and prothioconazole, respectively; for spring wheat, $\bar{C}_{I N D}$ was 46 and $54 \%$ for the same two fungicides. Here, we found that $\bar{I}$ was 7 and $11 \%$ for soft-red winter wheat treated with tebuconazole and prothioconazole, respectively, and 13 and $18 \%$ for spring wheat treated with these products (Table 2). Overall, the larger values for $\bar{I}$ found here for spring wheat can be attributed to both the higher $\bar{C}_{I N D}$ found for FHB control and the lower yields (overall) for spring compared with soft-red winter wheat.

TABLE 5. Estimated probabilities of achieving a positive yield response and responses $>250$ and $500 \mathrm{~kg} / \mathrm{ha}$ relative to the untreated check at different levels of Fusarium head blight intensity, based on mean effect sizes and among-study variances from a multivariate random-effects meta-analysis of the effects of triazolebased fungicide on wheat grain yield

\begin{tabular}{|c|c|c|c|c|c|c|}
\hline \multirow[b]{3}{*}{ Baseline, fungicide ${ }^{a}$} & \multicolumn{6}{|c|}{ Probability of a response ${ }^{b}$} \\
\hline & \multicolumn{2}{|c|}{$p_{+}$} & \multicolumn{2}{|c|}{$p_{250}$} & \multicolumn{2}{|c|}{$p_{500}$} \\
\hline & Spring & Winter & Spring & Winter & Spring & Winter \\
\hline TEBU & 0.95 & 0.80 & 0.61 & 0.32 & 0.15 & 0.04 \\
\hline PROP & 0.92 & 0.72 & 0.44 & 0.16 & 0.04 & $<0.01$ \\
\hline PROT & 0.97 & 0.88 & 0.78 & 0.51 & 0.35 & 0.13 \\
\hline TEBU+PROT & 0.93 & 0.86 & 0.71 & 0.57 & 0.36 & 0.23 \\
\hline TEBU & 0.98 & 0.92 & 0.80 & 0.53 & 0.31 & 0.11 \\
\hline PROP & 0.98 & 0.89 & 0.69 & 0.38 & 0.15 & 0.03 \\
\hline PROT & $>0.99$ & 0.99 & 0.98 & 0.90 & 0.80 & 0.54 \\
\hline TEBU+PROT & 0.99 & 0.99 & 0.95 & 0.90 & 0.78 & 0.65 \\
\hline METC & $>0.99$ & $>0.99$ & $>0.99$ & 0.98 & 0.92 & 0.68 \\
\hline
\end{tabular}

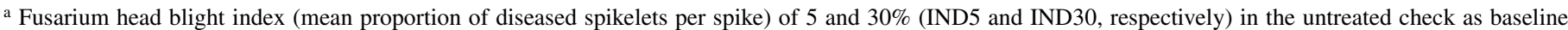
values from a multivariate meta-analysis in which mean disease index in the check was used a continuous moderator or predictor of the effect of fungicides used for Fusarium head blight control on wheat grain yield. Active ingredients TEBU = tebuconazole, PROP = propiconazole, PROT $=$ prothioconazole, and METC $=$ metconazole.

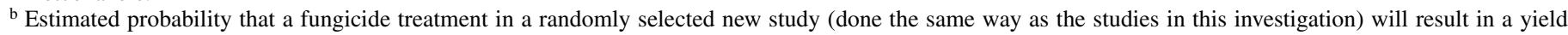
increase over the untreated check $\left(p_{+}\right)$, an increase of at least $250 \mathrm{~kg} / \mathrm{ha}$ over the check $\left(p_{250}\right)$, and an increase of at least $500 \mathrm{~kg} / \mathrm{ha}$ over the check $\left(p_{500}\right)$ for spring and soft-red winter wheat. For each active ingredient, the probabilities were estimated for fixed baseline index levels (5 and $30 \%$ IND) and not for separate subsets of the studies with these index levels. 
Although not explicitly considered by Madden and Paul (22), utilization of the modeling results in that article leads to the prediction that the mean increase in yield on an absolute $(\mathrm{kg} / \mathrm{ha})$ scale relative to the check $(\bar{D})$ would be directly proportional to the product of FHB index in the check plots and $\bar{C}_{I N D}$, with no effect of the disease-free yield on $\bar{D}$. Given that the levels of FHB index were similar for spring and soft-red winter wheat, the higher values of $\bar{D}$ found here for spring wheat would be primarily attributable to the higher levels of $\bar{C}_{I N D}$ found previously for percent disease control in spring wheat compared with soft-red winter wheat (33). Thus, even though the disease-free wheat yield is higher, in general, for soft-red winter than for spring wheat, the yield increase due to a fungicide application was higher for spring wheat.

As is usual with meta-analyses (13,32-34), a random-effects model fitted the data better than a fixed-effects model, and the extent of the heterogeneity among studies (quantified by the $R^{2}$ index of Higgins and Thompson [13]) of yield increase due to fungicide treatment was relatively large. This indicates that there was not a common (single) treatment effect on yield (or test weight) for any given fungicide across all studies but, instead, a population of treatment effects that was quantified by the estimated mean effect size $(\bar{D})(42,45)$. One source of heterogeneity among studies in treatment effect is the variation in environmental conditions for disease development (FHB and other diseases), variability of fungicide applications in spite of a standard protocol, as well as the aggressiveness of the pathogen strains used in the studies. Although there were no direct data available on environmental and other background conditions for all the studies, the level of disease index in the check $(B)$ in each study served as a surrogate measure $(31,33)$ of environmental favorability and pathogen aggressiveness. Utilization of a moderator variable of this type - considered a baseline risk variable in the meta-analysis literature $(1,5)$ - is common in medical statistics $(1,2,5)$ to reflect a general underlying risk of a particular outcome for experimental units that were not treated within studies. Our results clearly showed that disease index in the check (as the baseline risk moderator variable) did affect the estimated mean effect size, as anticipated by the modeling results in Madden and Paul (22), with estimated expected difference between the treatment and control yield (as well as percentage yield difference) increasing with the baseline risk. The evaluated fungicides can still be directly compared with each other regarding their expected effects on yield without consideration of the baseline risk of disease, either across wheat types or for each type separately (Tables 1 and 2) but use of the disease index in the check was required to estimate the magnitude of the expected treatment effects on yield (e.g., for conditions of low or high disease development).

The baseline-risk result may be attributed to differences in the relative degree of disease control achieved at high and low FHB intensities. In a previous investigation, Paul et al. (33) found little effect of FHB disease index in the check on the percent control of FHB index by fungicides. The previous investigation, however, dealt directly with the log of the ratio of disease index in the treatment (numerator) and check (denominator) as the expected effect size; for the ratio (or log ratio) to remain unchanged as the denominator (baseline risk) increased, the numerator also would have to increase. Thus, the difference in FHB index between a fungicide treatment and check increased as FHB in the check increased in this system. That previous assessment of baseline risk required a more complex analysis than required (or used) here because, in Paul et al. (33), FHB index was a component of the response vector (because treatment effect on disease index was of interest) and not just a moderator variable.

The associations between FHB disease index, yield, and fungicide efficacy reported by Paul et al. $(32,33)$ and Madden and Paul (22) and observed in this investigation were somewhat contrary to those reported by Hollingsworth et al. (14) on spring wheat in Minnesota, and Ransom and McMullen (38) on hard winter wheat in North Dakota. In the latter two studies, experiments were conducted under conditions of natural infection, over multiple growing seasons, using cultivars with different levels of FHB resistance and possibly "tolerance" $(26,29)$. In both of those investigations, averaged across cultivars, mean percent FHB reduction due to fungicide application was higher in the low FHB environment than in the moderate or high FHB environment, a result which was not found with a meta-analysis of $>100$ studies for spring and soft-red winter wheat $(32,33)$. However, mean percent yield increase relative to the untreated check was higher in the high-FHB environment than in the low-FHB environment, which is in agreement with the results in our current investigation. Disagreement in percent disease control may be explained by the fact that fungicide efficacy has been shown to be confounded by the relative FHB resistance of the cultivars being treated $(14,28$, 38). Greater percent control is often achieved when more resistant cultivars are treated with a fungicide than when susceptible cultivars are treated $(14,28,38)$.

Other confounding factors that could lead to variable yield and test weight responses to fungicide treatments are the presence (and intensity) of foliar diseases and the physiological effects of fungicide on yield in the absence of any disease $(7,31)$. The triazole fungicides evaluated here are all very effective against foliar diseases if applied at the proper time $(14,28,38)$. Assessments of foliar diseases were not available for most studies in this meta-analysis and, thus, could not be used as moderator variables in an analysis. It is certainly possible that a portion of the treatment effects could be due to foliar disease control. It is even more likely that variation in foliar disease intensity (or degree of control of foliar diseases) across studies contributed to the nonzero among-study variances found for effects of treatment on yield and test weight. However, it should be noted that, for the data from the UFTs that were analyzed here, fungicides were applied at GS 10.5.1, which is (considerably) later than the ideal time for foliar disease control $(6,30)$. This, combined with the knowledge of the relationship between yield and FHB index (22) and the direct effects of the triazoles on FHB control $(11,25$, $27,32,33)$, and the fact that all studies were conducted under FHB-favorable conditions, makes it reasonable to conclude that a major portion of the yield and test weight responses to fungicide treatment found in this investigation can be attributed to the control of FHB.

Prediction of study outcomes (with associated prediction intervals) - rather than just estimation of expected effect sizes and hypotheses testing - is one of the major advantages of randomeffect meta-analysis (44), even though this application is usually overlooked by investigators. Within the framework of statistical prediction, and utilizing the estimated expected effect-sizes and among-study variances $(1,35,36)$, we performed a risk analysis by determining the probability of yield increase (in a randomly selected study) exceeding specified constants (Table 5). At high disease index $(30 \%)$, the probability of a nonzero yield increase $\left(p_{+}\right)$was high (mostly, $\geq 0.98$ ) for all the fungicide treatments considered in this investigation, for both spring and soft-red winter wheat. The probability of yield exceeding higher cut-offs declined as the cut-offs increased, and the probability of a yield increase of at least $500 \mathrm{~kg} / \mathrm{ha}(\approx 8$ bushels per acre) was $>0.75$ (i.e., $p_{500}>0.75$ ) only for metconazole, tebuconazole+prothioconazole, and prothioconazole applied to spring wheat. With softred winter wheat, none of the treatments resulted in a $p_{500}$ value $>0.7$. At lower disease index (5\%), all the risk probabilities were (considerably) lower than at $30 \%$ index, especially for the probabilities of yield increase exceeding 250 and $500 \mathrm{~kg} / \mathrm{ha}$. Although all fungicide treatments resulted in reasonably large $p_{+}$ values (generally, $p_{+}>0.85$ ), none of the treatments resulted in a $p_{500}$ value $>0.40$ for spring wheat or $>0.25$ for soft-red winter wheat at this lower baseline disease index. 
Based on these results, we conclude that triazole-based fungicides used for FHB and DON management do contribute to significant mean yield and grain test weight increases, and that the magnitude of these responses varies with the active ingredient of the fungicide, wheat type, and background FHB intensity (as a reflection of the environmental and other conditions that favor disease development in wheat plots). Quantitative estimates of the overall expected effect sizes (mean differences or percentage changes), the estimated expected effect sizes as influenced by wheat type and FHB intensity, and the probabilities of yield exceeding specified (cut-off) constants are all of direct value for current efforts to evaluate the economics of fungicide applications to manage FHB and DON contamination of harvest grain. In general, metconazole, tebuconazole+prothioconazole, and prothioconazole were superior to the other two fungicides in terms of yield increase, although their effect on yield was lower for softred winter compared with spring wheat, and reduced at lower compared with higher disease index. Moreover, based on the calculated $p_{500}$ values, these three fungicides resulted in a reasonably high chance of a least a $500-\mathrm{kg} / \mathrm{ha}$ yield increase only when conditions were very favorable for epidemics (as measured by disease index). However, because other work shows that integration of multiple tactics is more effective at controlling FHB and DON than simple use of fungicides alone, and the fact that FHB is unlikely to be the only disease in a field and that wheat yield depends on more than the intensity of any one disease, further comprehensive studies are needed to evaluate yield and test-weight responses to fungicides in integrated FHB management programs under a range of foliar disease pressures, cultivar susceptibilities, and environmental conditions. These factors can all influence the economic benefit of using fungicides for FHB and DON management $(14,38)$.

\section{ACKNOWLEDGMENTS}

Salaries and research support were provided by state and federal funds to the Ohio Agricultural Research and Development Center (OARDC). This investigation is based upon work supported, in part, by the United States Department of Agriculture (USDA; Agreement No. 59-0790-4112). Further support was supplied by USDA-CSREES Special Grant 2008-34493-19444. This is a cooperative project with the U.S. Wheat \& Barley Scab Initiative (USWBSI). We thank all the researchers who have contributed to the Uniform Fungicide Trials of the USWBSI. Any opinions, findings, conclusions, or recommendations expressed in this publication are those of the authors and do not necessarily reflect the view of the United States Department of Agriculture.

\section{LITERATURE CITED}

1. Arends, L. R., Hoes, A. W., Lubsen, J., Grobbee, D. E., and Stijnen, T. 2000. Baseline risk as predictor of treatment benefit: Three clinical metare-analyses. Stat. Med. 19:3497-3518.

2. Arends, L. R., Voko, Z., and Stijnen, T. 2003. Combining multiple outcome measures in a meta-analysis: An application. Stat. Med. 22:1335-1353.

3. Bai, G., and Shaner, G. 1994. Scab of wheat: Prospects for control. Plant Dis. 78:760-766.

4. Boyacioglu, D., Hettiarachchy, N. S., and Stack, R. W. 1992. Effect of three systemic fungicides on deoxynivalenol (vomitoxin) production by Fusarium graminearum in wheat. Can. J. Plant Sci. 72:93-101.

5. Brand, R, and Kragt, H. 1992. Importance of trends in the interpretation of an overall odds ratio in the meta-analysis of clinical trials. Stat. Med. 11:2077-2082.

6. Cook, R. J., Hims, M. J., and Vaughan, T. B. 1999. Effects of fungicide spray timing on winter wheat disease control. Plant Pathol. 48:33-50.

7. Grossmann, K., Kwiatkowski, J., and Caspar, G. 1999. Regulation of phytohormon level, leafsenescence and transpiration by the strobilurine kresoximmethyl in wheat (Triticum aestivum). J. Plant Physiol. 154:805-808.

8. Hedges, L. V., Gurevitch, J., and Curtis, P. S. 1999. The meta-analysis of response ratios in experimental ecology. Ecology 80:1150-1156.

9. Hedges, L. V., and Olkin, I. 1980. Vote-counting methods in research synthesis. Psychol. Bull. 88:359-369.
10. Hershman, D., and Draper, M. 2004. Analysis of 2004 uniform fungicide trials across locations and wheat classes. Pages 318-319 in: Proc. 2nd Int. Symp. Fusarium Head Blight, Orlando, FL. Michigan State University.

11. Hershman, D. E., and Milus, E. A. 2002. Analysis of the 2002 uniform wheat fungicide and biocontrol trials across locations. Pages 82-87 in: Proc. 2002 Natl. Fusarium Head Blight Forum, Erlanger, KY. Michigan State University.

12. Hershman, D. E., and Milus, E. A. 2003. Performance of Folicur in Fusarium head blight uniform fungicide trials, 1998-2003. Pages 81-82 in: Proc. 2003 Natl. Fusarium Head Blight Forum, Bloomington, MN. Michigan State University.

13. Higgins, J. P. T., and Thompson, S. G. 2002. Quantifying heterogeneity in a meta-analysis. Stat. Med. 21:1539-1588.

14. Hollingsworth, C. R., Motteberg, C. D., Wiersma, J. V., and Atkinson, L. M. 2008. Agronomic and economic responses of spring wheat to management of Fusarium head blight. Plant Dis. 92:1339-1348.

15. Homdork, S., Fehrmann, H., and Beck, R. 2000. Effects of field application of tebuconazole on yield, yield components and the mycotoxin content of Fusarium-infected wheat grain. J. Phytopathol.148:1-6.

16. Hunter, J. E., and Schmidt, F. L. 2004. Methods of Meta-Analysis: Correcting Error and Bias in Research Findings, 2nd ed. Sage Publications Inc., Thousand Oaks, CA.

17. Large, E. C. 1954. Growth stages in cereals. Plant Pathol. 3:128-129.

18. Lipsey, M. W., and Wilson, D. B. 2001. Practical Meta-Analysis. Sage Publications Inc., Thousand Oaks, CA.

19. Littell, R. C., Milliken, G. A., Stroup, W. W., Wolfinger, R. D., and Schabenberger, O. 2006. SAS for Mixed Models, 2nd ed. SAS Institute, Cary, NC.

20. Lu, G., and Andes, A. E. 2004. Combination of direct and indirect evidence in mixed treatment comparisons. Stat. Med. 23:3105-3124.

21. Madden, L. V., Hughes, G., and van den Bosch, F. 2007. The Study of Plant Disease Epidemics. American Phytopathological Society, St. Paul, $\mathrm{MN}$.

22. Madden, L. V., and Paul, P. A. 2009. Assessing heterogeneity in the relationship between wheat yield and Fusarium head blight intensity using random-coefficient mixed models. Phytopathology 99:850-860.

23. Martin R. A., and Johnston H. W. 1982. Effects and control of Fusarium diseases of cereal grains in the Atlantic Provinces. Can. J. Plant Pathol. 4:210-216.

24. McMullen, M., Jones, R., and Gallenburg, D. 1997. Scab of wheat and barley: A re-emerging disease of devastating impact. Plant Dis. 81:13401348.

25. McMullen, M., Milus, G., and Prom, L. 1999. 1999 Uniform fungicide trials to identify products effective against Fusarium head blight in wheat. Pages 64-68 in: Proc. 1999 Natl. Fusarium Head Blight Forum, Sioux Falls, SD. Michigan State University.

26. Mesterházy, Á. 1995. Types and components of resistance to Fusarium head blight of wheat. Plant Breed. 114:377-386.

27. Mesterházy, Á, and Bartók, T. 1997. Effect of chemical control on FHB and toxin contamination of wheat. Cereal Res. Commun. 25:781-783.

28. Mesterházy, Á., Bartók, T., and Lamper, C. 2003. Influence of wheat cultivar, species of Fusarium, and isolate aggressiveness on the efficacy of fungicides for control of Fusarium head blight. Plant Dis. 87:1107-1115.

29. Mesterházy, Á., Bartók, T., Mirocha, C. G., and Komoroczy, R. 1999. Nature of wheat resistance. Plant Breed. 118:97-110.

30. Milus, E. A., and Chalkley, D. B. 1997. Effect of previous crop, seedborne inoculum, and fungicides on development of Stagonospora blotch. Plant Dis. 81:1279-1283.

31. Parry, D. W., Jenkinson, P., and McLeod, L. 1995. Fusarium ear blight (scab) in small grain cereals-a review. Plant Pathol. 44:207-238.

32. Paul, P. A., Lipps, P. E., Hershman, D. E., McMullen, M. P., Draper, M. A., and Madden, L. V. 2007. A quantitative review of tebuconazole effect on Fusarium head blight and deoxynivalenol content in wheat. Phytopathology 97:211-220.

33. Paul, P. A., Lipps, P. E., Hershman, D. E., McMullen, M. P., Draper, M. A., and Madden, L. V. 2008. Efficacy of triazole-based fungicides for Fusarium head blight and deoxynivalenol control in wheat: A multivariate meta-analysis. Phytopathology 98:999-1011.

34. Paul, P. A., Lipps, P. E., and Madden, L. V. 2005. Relationship between visual estimates of Fusarium head blight intensity and deoxynivalenol accumulation in harvested wheat grain: A meta-analysis. Phytopathology 95:1225-1236.

35. Piepho, H.-P. 1998. Methods for comparing the yield stability of cropping systems - a review. J. Agron. Crop Sci. 180:193-213.

36. Piepho, H.-P., and McCulloch, C. E. 2004. Transformations in mixed models: Application to risk analysis for a multivariate trial. J. Agric. Biol. Environ. Stat. 9:123-137.

37. Pirgozliev, S. R., Edwards, S. G., Hare, M. C., and Jenkinson, P. 2003. Strategies for the control of Fusarium head blight in cereals. Eur. J. Plant 
Pathol. 109:731-742.

38. Ransom, J. K., and McMullen, M. V. 2008. Yield and disease control on hard winter wheat cultivars with foliar fungicides. Agron. J. 100:11301137.

39. Raudenbush, S. W., Becker B. J., and Kalaian H. 1988. Modeling multivariate effect sizes. Psychol. Bull. 103:111-120.

40. Riley, R. D., Abrams, K. R., Lambert, P. C., Sutton, A. J., and Thompson, J. R. 2007. An evaluation of bivariate random-effects meta-analysis for the joint synthesis of two correlated outcomes. Stat. Med. 26:78-97.

41. Snijders, C. H. A. 1990. Fusarium head blight and mycotoxin contamination of wheat, a review. Neth. J. Plant Pathol. 96:187-198.

42. Sutton, A. J., and Higgins, J. P. T. 2008. Recent developments in meta- analysis. Stat. Med. 27:625-650.

43. Tuite, J., Shaner, G., and Everson, R. J. 1990. Wheat scab in soft red winter wheat in Indiana in 1986 and its relation to some quality measures. Plant Dis. 74:959-962.

44. van Houwelingen, H. C., Arends, L. R., and Stijnen, T. 2002. Advanced methods in meta-analysis: Multivariate approach and meta-regression. Stat. Med. 21:589-624.

45. Whitehead, A. 2002. Meta-Analysis of Controlled Clinical Trials. John Wiley and Sons, West Sussex, England.

46. Willocquet, L., Aubertot, J. N., Lebard, S., Robert, C., Lannou, C., and Savary S. 2008. Simulating multiple pest damage in varying winter wheat production situations. Field Crops Res. 107:12-28. 